\title{
Editorial
}

\section{Should psychiatry become Social Neuroscience?}

Psychiatry is the branch of medicine that demands a highly careful appreciation and understanding of psychological, as well as social and biological aspects of patients and their health problems, and for many psychiatrists, this complexity is at the heart of the medical specialty's appeal (1).

Dealing with this complexity in a pragmatic, clinically effective manner is the core business of psychiatry.

Viewing clinical issues and entities from the position that they have either a 'social' or a 'biological' origin since the early part of the 20th century have been a controversy not only within the psychiatric profession but also among lay people and in the public in general.

This type of thinking, still common in today's postFreudian era of psychiatric theory and practice, is often driven by ideology and politics, and is an impediment to public understanding, the development of effective services and therefore to patient care (2).

We humans live in 'two worlds': a world of biology and physical causes, to which our brain also belongs, and a world of meaning, symbols, discursive contexts and interpersonal relationships (3).

These two worlds each have their own laws and processes, which have been studied separately for centuries by neuroscience-oriented researchers on the one hand and researchers of the psychological/social domain on the other.

Reconciling these two positions in relation to defining the nature of mental illness, not to mention delineating different disease entities, has so far not been a great success.

In the present issue of Acta Neuropsychiatrica, de Leon (4) discusses the above-mentioned problems and rightly points out the reductionistic biological views by leading psychiatrists of the 19th century (Meynert, Wernicke and, partly, Kraepelin), contrasting the purely psychological viewpoint of Freud - not considering brain mechanisms in this decade-long dominating theoretical framework and clinical practise.

Both positions were criticised strongly in the early 20th century by Karl Jaspers (5), who considered himself more a psychopathologist than a psychiatrist. Jaspers' main contribution to the psychiatric science was his proposal that psychiatry is a hybrid discipline requiring two methods, Explaining from the natural sciences and Understanding from the social sciences.
Jaspers drew 'ideal types' from Max Weber's (1864-1920) social theory.

$\mathrm{He}$ anticipated that as knowledge advanced ideal typical disease entities would become real disease entities.

This became the destiny of general paralysis as knowledge of its neuropathology, serology and microbiology emerged. With the final edition of General psychopathology, Jaspers anticipated the transition of schizophrenia from ideal typical to real disease entity (6).

De Leon (4) criticises recent attempts at improving the classification of psychiatric diseases, in particular those of the neo-Kraepelinians (7) and the so-called Social Neuroscience (8) based on the Research Domain Criteria (RDoC) published by the US National Institute of Mental Health (9).

De Leon (4) experiences a déjà vu comparing the disillusionment with respect to explaining mental illness after the progress in neuroscience in the late 19th century and again in the beginning of the 21 st century in spite of an explosion of knowledge within methods such as brain imaging, pharmacology and molecular genetics.

The progresses then and now seem to have had limited relevance to the elucidation of the pathophysiology of mental disorders.

There is no doubt that psychiatry's basic discipline, descriptive psychopathology, for decades has not had the same role in psychiatric research as it had in the days of Jaspers' early criticisms.

It is therefore interesting to see groups of psychopathology researchers of today constructively arguing for a refinement of evaluation and classification of symptoms, partly following Jaspers' idea of the hybridity of psychiatry, and at the same time being highly critical of the $\mathrm{RDoC}$ programme - Parnas thus calling it 'psychiatry without a psyche' (10).

Ghaemi (11) in a discussion of today's neoKraepelinian nosology, which may lead to overdiagnosis of psychiatric syndromes (nosologomania), calls for Jaspers' critique of Kraepelin for a reformulation of the present nosology. He concluded that we need to better understand which diagnoses carry with them the implication of being biological disease entities, requiring more implication on medication treatment, and which diagnoses are different. Here we might 


\section{Bolwig}

well look at Jaspers' ideal type method so as to improve our current neo-Kraepelin nosology.

By all means, it remains so far a major problem, that we do not have rigorously tested, reproducible, clinically actionable biomarkers for any psychiatric disorder.

The concept of Social Neuroscience was introduced early in the 'Decade of The Brain' (the 1990s) and it brings together the increasingly powerful tools of neuroscience to explore the brain mechanisms underlying social interaction and behaviours.

With both the overlapping and similarly rapidly developing fields of cognitive neuroscience and affective neuroscience together with improved tools like functional neuroimaging, Social Neuroscience holds promises for further understanding of many of the clinical problems experienced by psychiatric patients. Psychiatry has currently been warned either to become a 'clinical neuroscience' abandoning descriptive psychopathology $(3,12)$ or to adopt a psychosocial paradigm, conceptualising mental disorders in terms of understandable responses to adverse environmental situations or problematic interpersonal relationships (3). Social Neuroscience is not only concerned with biological mechanisms using neuroscience methodology - it is also helpful in elucidating the perception and understanding of others' mental states and the development and maintenance of social bonds are under study $(13,14)$.

In spite of the above-mentioned criticism raised from some quarters, the interdisciplinary area of Social Neuroscience may well be the 'basic science' that most closely fits the integrative nature of psychiatry as a clinical discipline (3).

To quote Craddock (1), it will hopefully bring an end to the destructive and misguided 'social' versus 'biological' in psychiatry.

Tom G. Bolwig Professor of Psychiatry Emeritus, Copenhagen Psychiatry Center, University of Copenhagen Copenhagen, Denmark E-mail: bolwig@tdcspace.dk

\section{Acknowledgements}

Dr. Bolwig has received grant/research support from the Lundbeck Foundation and has been on advisory board for Eli Lilly.

\section{Conflicts of Interest}

None.

\section{References}

1. Craddock N. Social neuroscience: bringing an end to the destructive and misguided 'social' versus 'biological' in psychiatry. World Psychiatry 2014;13:140-141.

2. Craddock N, Antebi D, Attenburrow MJ et al. Wake-up call for British psychiatry. Br J Psychiatry 2008;193:6-9.

3. Maj M. Social neuroscience as an ideal basic science for psychiatry. World Psychiatry 2014;13:105-106.

4. DE LEON J. Is psychiatry only neurology? Or only abnormal psychology. Déjà vu after 100 years. Acta Neuropsychiatr 2015;27:69-81.

5. JASPERS K. General psychopathology, Translated from German by Hoeing $\mathbf{J}$ and Hamilton MH, 7th edn. Manchester, UK: Manchester University Press, 1963.

6. WALKER C. Karl Jaspers on the disease entity: Kantian ideas and Weberian ideal types. Hist Psychiatry 2014; 25:317-334.

7. Robins E, Guze SB. Establishment of diagnostic validity in psychiatric illness: its application to schizophrenia. Am J Psychiatry 1970;16:983-987.

8. Cacioppo JT, Cacioppo S, Dulawa S, Palmer Aa. Social neuroscience and its potential contribution to psychiatry. World Psychiatry 2014;13:131-139.

9. Insel T, Cuthbert B, Garvey $\mathrm{M}$ et al. Research Domain Criteria (RDoC): toward a new classification framework for research on mental disorders. Am J Psychiatry 2010;167:748-751.

10. PARnas J. The RDoC program: psychiatry without a psyche? World Psychiatry 2014;13:46-47.

11. Ghaemi SN. Nosologomania: DSM \& Karl Jaspers' critique of Kraepelin. Philos Ethics Humanit Med 2009; 4:10-17.

12. Insel T, Quirion R. Psychiatry as a clinical neuroscience discipline. J Am Med Assoc 2005;294:2221-2224.

13. Haxby JV, Hoffman EA, Gobbini MI. Human neural systems of face recognition and social communication. Biol Psychiatry 2002;51:59-67.

14. Adolphs R, Anderson D. Social and emotional neuroscience. Curr Opin Neurobiol 2013;23:291-293. 